\title{
New Approaches to Study Fresh Pork Sausage Microbiota
}

\author{
Tiziana Maria Sirangelo \\ Department of Life Sciences, University of Modena and Reggio Emilia, Modena, Italy.
}

*Corresponding Author: Tiziana Maria Sirangelo, Department of Life Sciences, University of Modena and Reggio Emilia, Modena, Italy.

\begin{abstract}
The study of the pork sausage microbiota, especially of the initial microbial ecology, is strictly related to the product shelf life, whose extension is nowadays a significant challenge. In this review the microbial community generally found in fresh pork sausage and its Specific Spoilage Organisms (SSOs) are described. The SSOs key role is underlined, in fact, they may be used to predict the shelf-life of the product, to aid the microbiological inspections and to design new preservation or production methods. The main pork sausage deteriorations are also treated and the influence of high level of nutrients, including glucose, lactic acid, nitrogenous compounds, and amino acids, on bacteria growth is underlined. Furthermore, the more significant current pork sausage microbiological investigations are discussed, especially those using new approaches and innovative techniques, as metagenomics. Although these studies improve our knowledge about this meat product microbiota, a detailed overview of the microbial community during its shelf life is still necessary. As a whole, this contribute aim to be a clear and sufficiently exhaustive investigation initially useful for all researchers studying meat and sausage microbiota.
\end{abstract}

Keywords: Meat, Sausage, spoilage, shelf life, food microbiology, metagenomics

\section{INTRODUCTION}

The basic raw materials used in fresh sausage manufacture is generally the mixing of lean pork meat and fat. The ratio of lean to fat has a decided bearing on the quality of the product. In addition to meat, other ingredients are used, such as spices, water, and salt in variable amounts. Sugars and ascorbate may frequently be added in small amounts.

The fresh pork sausage is a perishable product that over the time can be colonized by spoilage bacteria that can make it inacceptable because of undesirable modifications of sensorial properties, such as appearance, texture, odor, and flavor [1] [2]. Indeed, being a fresh product, no thermal treatment is applied during the production process [3]. Furthermore, this product has a meat matrix with high water activity and slightly acidic $\mathrm{pH}$. High level of nutrients including glucose, lactic acid, nitrogenous compounds, and amino acids allows also growth of bacteria.

Fresh sausages are generally available in the market raw or packaged under modified atmosphere (MAP) [4,5]. Temperatures and MAP are the most important exogenous factors affecting growth of microorganism [6]. Generally fresh sausages are conserved refrigerated in MAP to maintain the red color of the meat. The refrigeration of raw meat slows down growth of bacteria, allowing selection and blooming of psychrotrophic aerobic and aerotolerant species.

The pork sausage shelf life, whose extension is nowadays a main research aim, is strictly linked to the composition of the initial microbiota, in both quantitative and qualitative terms. Pathogenic species, such as Listeria monocytogenes, Escherichia coli O157:H7, Yersinia enterocolitica, and Salmonella, can be present $[7,8]$.

\section{FReSh Pork SAusage Microbiota}

Exploring the diversity of microorganisms in the sausage is a relevant focus of research, since a better understanding of the role of bacterial populations in food quality and safety greatly impacts on both health, sustainability, and economy. Knowledge of the Specific Spoilage Organisms (SSOs) can ultimately be used to predict the shelf-life of the product, to aid the microbiological inspections and to design new preservation or production methods. Spoilage can be defined as any change in a food 
product that makes it unacceptable to the consumer from a sensory point of view. Microbial spoilage is the most common cause of sausage spoilage and may manifest itself as visible growth (slime, colonies), as textural changes (degradation of polymers) or as off-flavors [9]. In the case of fresh pork sausage, microbial spoilage leads to the development of off-flavors, oxidative rancidity, discoloration, gas production and, often, slime formation.

The meat microbiota is often divided into a core dominant population and a product specific subdominant population [6]. Variations in these complex microbial assemblages can result in different forms and degrees of spoilage [10,11].

It is known that bacteria responsible for spoilage of fresh sausage are mainly Firmicutes, and in particular Carnobacteria, Lactobacilli, Leuconostocs, and Brochothrix thermosphacta [1-3]. Proteobacteria, such as Serratia, Yersinia, Pseudomonas, Acinetobacter, can be present and to influence sensorial properties of this meat product. Staphylococci, micrococci, and Bacteroidetes are also recurrent [12].

In a study [13] the use of culture-dependent methods showed that the populations of mesophilic bacteria and Lactic Acid Bacteria (LAB) increased linearly over storage time. The PCR-DGGE method (a culture independent method consisting of an electrophoretic separation of the PCR product in a polyacrylamide gel) allowed a rapid identification of dominant communities present in sausages, particularly, 15 species and seven genera of bacteria that frequently constitute the sausage microbiota have been discriminated [3].

However, the microbial population that colonizes the fresh pork sausage is highly variable, depending on which groups of microbial taxa the product has been exposed to the environment. The muscle tissue in situ is essentially devoid of microorganisms, with the exception of low levels of organisms that have been detected in lymph nodes. After removal, this tissue is rapidly colonized: organisms are introduced onto the carcass surface through cross-contamination from the production environment, and organisms from spices can be introduced into the blended meat [1].

Traditional studies of the microbial populations found on meats and in meat production environments have associated spoilage of meats with broad groups of organisms, including members of the Proteobacteria (taxa belonging to the genera Actinobacter, Pseudomonas, Moraxella, Psychrobacter, Shewanella, and several members of the Enterobacteriaceae), the Bacilli (species of Bacillus, Brocothrix, Carnobacterium, Kurthia, Lactobacillus, Lactococcus, Leuconostoc, Pediococcus, Staphylococcus, and Weissella), and the Bacteroidetes (Bacteroides and Flavobacterium). Although these organisms are located in diverse phylogenetic space, they share in common the capacity for growth at refrigeration temperatures (psychrotrophic growth) and heterotrophic lifestyles on glucose, lipids, and amino acids, which are abundant in blended fresh ground meat products [1].

Furthermore, $\mathrm{NaCl}$ concentration drastically influences the composition of microbiota and the spoilage of the product [2].

\section{Pork Sausage Microbial Growth During Production Phases}

At packaging, microbial population can derive from cross contamination during slaughtering and successive operations, from the industrial environments where sausages are produced, and from ingredients (mainly spices) and casings [1,6].

The fresh meat generally has a pH between 5.5 and 5.8 and contains mainly protein and fat. Albeit in a very small percentage, glucose and other simple carbohydrates, are also present. They are able to support bacterial growth up to $109 \mathrm{CFU} / \mathrm{g}$. However, the preferred source of nourishment of the meat microbiota consists of proteins.

On the surfaces of the meats, at the end of the slaughter phase, a microbial population in an amount between 104 and $106 \mathrm{CFU} / \mathrm{g}$ is already present.

Microbial count tends to increase during the shredding stages for the preparation of raw sausages, in fact, the available surface considerably increases. Adding spices and subsequent handling further increase the number of microorganisms present [14].

The type of gas in MAP has a strong selection on the microbiota of meat. Generally, the increase of the $\mathrm{CO}_{2}$ concentration with limitation than that of $\mathrm{O}_{2}$ identifies a microbiota which is dominated by Gram-positive bacteria. This extend the sausage shelf-life. The composition of the microbiota of meat 
in MAP is strictly dependent on the storage temperature. The lactic acid bacteria predominate at temperatures near $0^{\circ} \mathrm{C}$, while those belonging to the Pseudomonas genus and the Enterobacteriaceae family can grow to very high counts and are favored by temperatures of $5-6^{\circ} \mathrm{C}$.

\section{Microbial Spoilage of Pork Sausage}

The progressive undesirable modifications of sensorial properties of pork sausage depends mainly by metabolic activity of microbiota along with chemical and biological reactions. These reactions that occur in raw meat consisting mainly in lipid oxidation and other transformations of meat enzymes $[15,16]$.

The main pork sausage deteriorations are described below.

SMELLS: This alteration of the meat is frequently associated with the use of amino acids by dominant populations of Pseudomonas. Glucose is the first nutrient to be metabolized by Pseudomonas and that is present in the meat only in small concentrations. At Pseudomonas levels approximately $107 \mathrm{CFU} / \mathrm{g}$ the first signs of alteration of the meat begin to be evident with the appearance of off-flavors similar to faint aroma of cheese. When the microbial population reaches charges of approximately $108 \mathrm{CFU} / \mathrm{g}$. and the glucose is depleted, smells are increasingly evident. Until malodorous substances as ammonia, dimethyl sulfide, dimethyl disulfide are produced from nitrogen compounds, other substrates are used.

VISCOSITY: When bacteria belonging to Pseudomonas, Lactobacillus, Micrococcus, ect., exceed the concentration of $5 \times 108 \mathrm{CFU} / \mathrm{g}$, exogenous components more or less viscous may take place. Some of these are the result of the production of exopolysaccharides from bacteria belonging to Lactobacillus genus.

FLAVORS: Generally the anomalous flavors are the result of microbial proliferations greater than $5 \times 108 \mathrm{CFU} / \mathrm{g}$; the $\mathrm{pH}$ reduction contributes to the unpleasant taste (due in part to the oxidation or microbial fermentation, in part to the Lactobacillus o Micrococcus proteolytic activity) and the anaerobic decomposition of proteins to the putrefaction taste.

COLOR: Areas of discoloration may be due to the development of Lactobacillus and Streptococcus, that originate with their metabolism to oxidative substances reacting with myoglobin of the meat. The natural browning of the meat itself is due to this phenomenon.

The meat coloration is visible from the earliest hours but it may be delayed preserving the meat in modified atmosphere.

\section{CURRENT InVESTigations: A SUMmary}

In a recent investigation [2], the influence of salt reduction (from $2.0 \%$ to $1.5 \%$ ) has been evaluated, in combination with two types of packaging, modified atmosphere (50\% mix of $\left.\mathrm{CO}_{2}-\mathrm{N}_{2}\right)$ and vacuum packaging, on the onset of spoilage and on the diversity of spoilage-associated to fresh pork sausage bacteria. After 21 days of storage at $8^{\circ} \mathrm{C}$, spoilage was easily observed, characterized by graying of the product and the production of gas and off-odors. The global spoilage intensity was more pronounced in samples stored under modified atmosphere than under vacuum packaging and in samples with the lower salt content. In this study, metagenomic 16S rRNA pyrosequencing (16S rDNA is one of most popular marker gene used in metagenomic studies, called also amplicon sequencing) revealed that the core community was composed of 6 Operational Taxonomic Unit or OTUs (Lactobacillus sakei, Lactococcus piscium, Carnobacterium divergens, Carnobacterium maltaromaticum, Serratia proteamaculans, and Brochothrix thermosphacta), whereas 13 OTUs taxonomically assigned to the Enterobacteriaceae, Enterococcaceae, and Leuconostocaceae families comprised a less-abundant subpopulation. This subdominant community was significantly more abundant when $2.0 \%$ salt and vacuum packaging were used, and this correlated with a lower degree of spoilage.

Another study [17] investigated also about the influence of salt reduction and showed how moderately $(22-25 \%)$ and greatly $(43-50 \%)$ reduction of $\mathrm{NaCl}$ affected yield, sensory quality and microbial growth in hotdog sausages, bacon, cooked cured ham and salami. The achieved results show as in sausages and ham, reduction from $2.2 \%$ to $1.7 \%$ and from $2.3 \%$ to $1.3 \%(\mathrm{w} / \mathrm{w})$, respectively, did not alter the sensory properties. In contrast, the sensory properties of bacon and salami were significantly affected already after a moderately reduction. 
Fresh pork sausage is produced without a microbial kill step and therefore it is chilled or frozen to control microbial growth. In a study [1], the microbiota in a chilled fresh pork sausage model produced with or without an antimicrobial combination of sodium lactate and sodium diacetate was studied using a combination of traditional microbiological methods and deep pyrosequencing of $16 \mathrm{~S}$ rRNA gene amplicons. Microbial populations rose from 102 to 106CFU/g within 15 days of storage at $4^{\circ} \mathrm{C}$, peaking at nearly $108 \mathrm{CFU} / \mathrm{g}$ by day 30 . Pyrosequencing revealed a complex community at day 0 , with taxa belonging to the Bacilli, Gammaproteobacteria, Betaproteobacteria, Actinobacteria, Bacteroidetes, and Clostridia. During storage at $4^{\circ} \mathrm{C}$, results displayed a complex succession, with species of Weissella and Leuconostoc that dominate the product at day 0 being displaced by species of Pseudomonas ( $P$. lini and P. psychrophila) within 15 days. By day 30, a second wave of taxa (Lactobacillus graminis, Carnobacterium divergens, Buttiauxella brennerae, Yersinia mollaretti, and a taxon of Serratia) dominated the population, and this succession coincided with significant chemical changes in the matrix. Treatment with lactate-diacetate altered the dynamics dramatically, yielding a monophasic growth curve of a single species of Lactobacillus (L. graminis), followed by a uniform selective die-off of the majority of species in the population. Of the six species of Lactobacillus that were routinely detected, L. graminis became the dominant member in all samples, and its origins were traced to the spice blend used in the formulation.

Another investigation to monitor fresh pork sausage ageing developed a new optoelectronic nose composed of seven sensing materials prepared by the incorporation of $\mathrm{pH}$ indicators and chromogenic reagents selective to metabolites into inorganic materials [18].

In [19], the effect of lacticin 3147, a novel heat-stable bacteriocin, produced by Lactococcus lactis DPC 3147 (that exhibits a broad-range inhibition spectrum similar to nisin), and nisin on the shelf life of fresh pork sausage and their ability to control pathogens (Clostridium perfringens DSM 756, Salmonella Kentucky AT1) and nonpathogenic Listeria innocua DPC 1770 was investigated.

\section{CONCLUSIONS AND DISCUSSION}

Albeit these above described investigations represent significant research studies about fresh pork sausage, nowadays, a detailed global view of its microbiota during the shelf life is necessary.

This in-depth analysis, in our opinion, it is appropriate to be developed by using new technologies, as next sequencing technologies (NGS), which contribute to food investigation advances by allowing to produce a larger volume of data at a price that is decreasing. For this reason, they may become a relevant tool for food microbiology and its application fields.

Furthermore, NGS has a great advantage over of more traditional culture independent analysis methods, in which only a fraction of the microbiota of the sample can be identified. In fact, in NGS a massive quantity of sequences are generated from a single sequencing run, with the possibility of obtaining a large amount of information in a relatively short time [20].

Finally, we consider appropriate the integration of different methods, such as, for example, approaches based on chemical analysis and metagenomics approach. In fact, the chemical analysis allows to evaluate the occurrence of $\mathrm{pH}$, organic acids, biogenic amines and the prevalent volatile compounds (VOCs). The metagenomic analysis allows a comprehensive picture of bacteria present in the samples. If the shotgun technique (a metagenomic technique for sequencing the entire genome of a given organism) is used, this allows to highlight changes in the evolution of microbial composition of foods, in contrast to the amplicon sequence method that typically is much more suitable for bacterial identification.

\section{REFERENCES}

[1] A.K. Benson, J. R. D. David, S.E. Gilbreth, G. Smith, J. Nietfeldt, R. Legge, J. Kim, R. Sinha, G.E. Duncan, J. Ma, I. Singh, "Microbial successions are associated with changes in chemical profiles of a model refrigerated fresh pork sausage during an 80-day shelf life study," Appl Environ Microbiol., vol. 80, pp. 5178-5194, 2014.

[2] L. Fougy, M-H. Desmonts, G. Coeuret, C. Fassel, E. Hamon, B. Hézard, M-C. Champomier-Vergès, S. Chaillou S., "Reducing salt in raw pork sausages increases spoilage and correlates with reduced bacterial diversity," Appl Environ Microbiol., vol. 82, pp. 3928 -3939, 2016.

[3] L. Cocolin, K. Rantsiou, L. Iacumin, R. Urso, C. Cantoni, G. Comi, "Study of the Ecology of Fresh Sausages and Characterization of Populations of Lactic Acid Bacteria by Molecular Methods," Appl Environ Microbiol., vol. 70, pp. 1883-1894, 2014. 
[4] P. Tremonte, E. Sorrentino, M. Succi, A. Reale, G. Maiorano, R. Coppola, "Shelf life of fresh sausages stored under modified atmospheres," Journal of Food Protection, vol. 68, pp. 2686-2692, 2005.

[5] E. Torrieri, F. Russo, R. Di Monaco, S. Cavella, F. Villani, F. Masi, "Shelf Life Prediction of Fresh Italian Pork Sausage Modified Atmosphere Packed,” Food Sci Tech Int., vol. 17, pp. 223-232, 2011.

[6] S. Chaillou, A. Chaulot-Talmon, H. Caekebeke, M. Cardinal, S. Christieans, et al., "Origin and ecological selection of core and food-specific bacterial communities associated with meat and seafood spoilage," ISME J., vol. 9, pp. 1105-1118, 2014.

[7] A. De Cesare, R. Mioni, G. Manfreda, "Prevalence of Listeria monocytogenes in fresh and fermented Italian sausages and ribotyping of contaminating strains," Int. J. Food Microbiol., vol. 120, pp. 124-130, 2007.

[8] S. Joutsen, K-T. Riikka, K. Hannu, "Growth and survival of Yersinia enterocolitica and Escherichia coli O157:H7 in fresh sausages," Journal of Food Safety and Food Quality, vol. 63, pp. 132-135, 2012.

[9] L. Gram et al., "Food spoilage - interactions between food spoilage bacteria," International Journal of Food Microbiology, vol. 78, pp. 79-97, 2012.

[10] B. Remenant, E. Jaffrès, X. Dousset, M-F. Pilet, M. Zagorec, "Bacterial spoilers of food: behavior, fitness and functional properties," Food Microbiol., vol. 45, pp. 45-53, 2015.

[11] A.I. Doulgeraki, D. Ercolini, F. Villani, G-JE. Nychas, "Spoilage microbiota associated to the storage of raw meat in different conditions," Int J Food Microbiol., vol. 157, pp. 130-141, 2012.

[12] F. Gardini, G. Tabanelli, R. Lanciotti, C. Montanari, M. Luppi, F. Coloretti, C. Chiavari, L. Grazia, "Biogenic amine content and aromatic profile of Salama da sugo, a typical cooked fermented sausage produced in Emilia Romagna Region (Italy),” Food Control, vol. 32, pp. 638-643, 2013.

[13] F.S. Dias, C.L. Ramos, R.F. Schwan, "Characterization of spoilage bacteria in pork sausage by PCRDGGE analysis," Food Sci. Technol. , vol.33 no.3, 2013.

[14] E. Nerbrink, E. Borch, "Evaluation of bacterial contamination at separate processing stages in emulsion sausage production," International Journal of Food Microbiology, vol. 20, pp. 37-44, 1993.

[15] C.J. Hugo, A. Hugo, "Current trends in natural preservatives for fresh sausage products," Trends in Food Science and Technology, vol. 45, pp.12-23, 2015.

[16] S.S. Kamdem, F. Patrignani, M.E. Guerzoni, "Shelf-life and safety characteristics of Italian Toscana traditional fresh sausage (Salsiccia) combining two commercial ready-to-use additives and spices," Food Control, vol. 18, pp. 421-429, 2007.

[17] M.D. Aaslyng, C. Vestergaard, A. GranlyKoch, "The effect of salt reduction on sensory quality and microbial growth in hotdog sausages, bacon, ham and salami," Meat Science, vol. 96, pp. 47-55, 2014.

[18] Y. Salinas, J. Ros-Lis, J.L.Vivancos, R. Martínez-Máñeza, M.D. Marcos, S. Aucejo, N. Herranz, I. Lorente, E. Garcia, “A novel colorimetric sensor array for monitoring fresh pork sausages spoilage," Food Control, vol. 35, pp. 166-176, 2014.

[19] A.G.M. Scannell, R.P. Ross, C. Hill, E.K. Arendt, “An Effective Lacticin Biopreservative in Fresh Pork Sausage,” Journal of Food Protection, vol. 63, pp. 370-375, 2000.

[20] D.C. Koboldt, K.M. Steinberg, D.E. Larson, R.K. Wilson, E.R.Mardis, "The next-generation sequencing revolution and its impact on genomics," Cell, vol. 155, pp. 27-38, 2013.

Citation: T. M. Sirangelo, "New Approaches to Study Fresh Pork Sausage Microbiota ", International Journal of Research studies in Microbiology and Biotechnology, vol. 4, no. 2, p. 1-5, 2018. http://dx.doi.org/10.20431/2454-9428.0402001

Copyright: (C) 2018 Authors. This is an open-access article distributed under the terms of the Creative Commons Attribution License, which permits unrestricted use, distribution, and reproduction in any medium, provided the original author and source are credited. 